\title{
Warty dyskeratoma
}

\author{
André Lencastre, MD, Sara Campos, MD, and Joana Cabete, MD \\ Lisboa, Portugal
}

Key words: acantholytic dyskeratosis; adnexal neoplasm; dermoscopy; follicular dyskeratoma; warty dyskeratoma.

\section{CLINICAL PRESENTATION}

A 65-year-old woman presented with an asymptomatic 5-mm pink papule on her left frontotemporal region (Fig 1). The patient noticed this lesion approximately 1 year earlier.

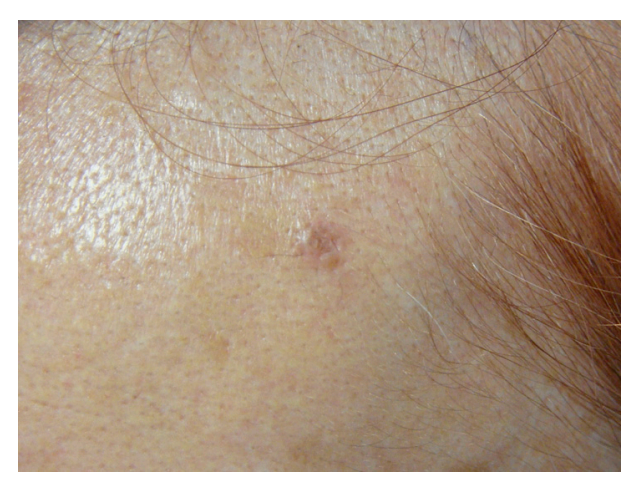

Fig 1. Warty dyskeratoma. Pink papule on the left frontotemporal region.

\section{DERMOSCOPIC APPEARANCE}

Manual dermoscopy revealed a pale, homogeneous area mottled by 3 brown to yellow marbled clods adjacent to several hair follicles (Fig 2).

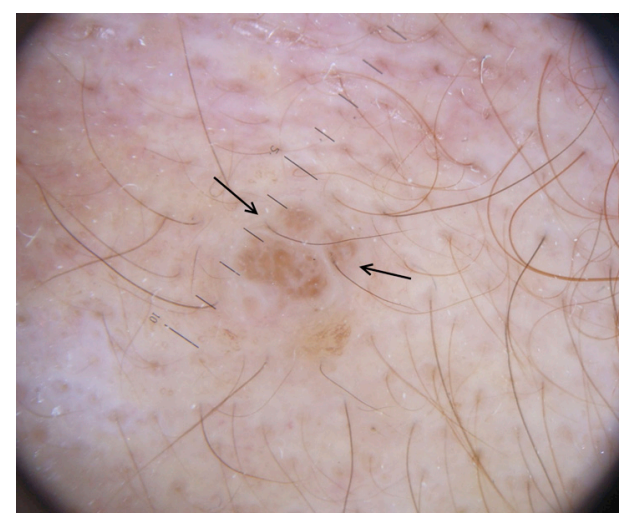

Fig 2. Manual dermoscopy of warty dyskeratoma. White homogeneous area with 3 yellow clods with intervening hair follicles (arrows). (Delta 20 dermatoscope [Heine Optotechnik, Herrsching, Germany] with Cyber-shot T90 camera [Sony, Tokyo, Japan]).

From the Serviço de Dermatologia, Hospital de Santo António dos Capuchos, Centro Hospitalar de Lisboa Central.

Funding sources: None.

Conflicts of interest: None declared.

Reprint requests: André Lencastre, MD, Serviço de Dermatologia, Hospital de Santo António dos Capuchos, Centro Hospitalar de
Lisboa Central, Alameda de Santo António dos Capuchos, 1169050 Lisboa. E-mail: lencastre.derm@gmail.com.

J Am Acad Dermatol 2016;75:e97-8.

0190-9622/\$36.00

(c) 2016 by the American Academy of Dermatology, Inc.

http://dx.doi.org/10.1016/j.jaad.2016.02.1157

Downloaded from ClinicalKey.com at Centro Hospitalar Lisboa Central August 22, 2016. For personal use only. No other uses without permission. Copyright $(2016$. Elsevier Inc. All rights reserved. 


\section{HISTOLOGIC DIAGNOSIS}

Histology revealed features of warty dyskeratoma, a cup-shaped epidermal proliferation with prominent dyskeratosis, acantholysis, a hyperkeratotic plug above, and a dense lymphocytic infiltrate underneath (Fig 3). This lesion was in apparent contiguity with at least 2 pilosebaceous units.

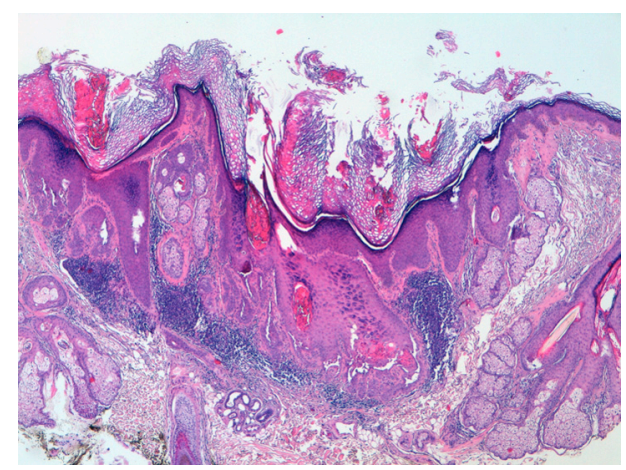

Fig 3. Histology of warty dyskeratoma. Cup-shaped epidermal proliferation with hyperkeratotic plug and prominent acantholytic dyskeratosis. (Hematoxylin-eosin stain; original magnification: $\times 40$.)

\section{KEY MESSAGE}

Warty dyskeratoma is an uncommon benign epidermal proliferation mainly seen on the head or neck of adults. The prominent histologic features of acantholysis and dyskeratosis make the diagnosis. Some architectural features reminiscent of a wartlike growth encouraged some authors to suggest a viral infection to be the cause. Absence of evidence for the former, and its relationship to the hair follicle, has prompted others to suggest the term "follicular dyskeratoma." ${ }^{11}$ It may be a more correct designation for an assumed adnexal neoplasm.

To our knowledge, this is the first description of dermoscopy of a warty dyskeratoma. This lesion demonstrated a coarse cobblestone pattern, where amidst a pale homogenous area, $\tan$ clods corresponded to hyperkeratotic plugs seen on histology. Recognition of these features may aid the dermatologist in the clinical diagnosis, although further reports of dermoscopy of these lesions are needed to ascertain specificity.

\section{REFERENCE}

1. Kaddu S, Dong H, Mayer G, Kerl H, Cerroni L. Warty dyskeratoma-"follicular dyskeratoma": analysis of clinicopathologic features of a distinctive follicular adnexal neoplasm. J Am Acad Dermatol. 2002;47(3):423-428. 